\section{Researching policy impacts}

\author{
Ruth E Malone
}

It is widely understood that policy-level interventions have had far greater effects on reducing tobacco use than individual-level measures. Yet, many continue to view the tobacco epidemic as a problem of individual decisions to use harmful products, rather than a problem of governments' failure to properly protect the public from those unnecessary, addictive and lethal products in the first place. The papers in this e-issue consider the multiple impacts of policy changes and point to the importance of how those impacts are measured, as well as what we decide to measure and why it matters.

The research-policy relationship, as noted by Warner and Tam in $2012,{ }^{1}$ is a complicated and sometimes cyclical one in which research influences policy adoption, policy adoption changes the environment and policy impacts may turn out to be different than anticipated, opening up new research areas. Many policies remain unevaluated, and such evaluations, given the complexity of policy contexts, are highly challenging to do well, requiring consideration of multiple factors that may not always be obvious. The paper by Been $e t a l^{2}$ is illustrative. They used an interrupted time series design to assess the effects of Scottish implementation of a national smoke-free policy on children's hospitalisations and deaths from respiratory infections. Using their prespecified model, they found a puzzling gradual increase in such hospitalisations. Post-hoc exploratory break point analyses demonstrated that the increase actually preceded the implementation of the law by 16 months. After accounting for this, the policy was found to be associated with a modest, gradual decrease in respiratory events.

But health outcomes are not the only relevant measures of policy impact. Policy often changes social environments, even changing how businesses operate, creating new research questions. Does banning smoking in gambling establishments hurt these businesses? Tauras et $a l^{3}$ studied the impact of a US state law prohibiting smoking on the gambling floors of casinos, showing that there was no significant negative economic impact to the casinos in terms of per capita admissions or revenues.

Correspondence to Professor Ruth E Malone, Social and Behavioral Sciences, University of California, San Francisco, San Francisco, CA 94118, USA; ruth.malone@ucsf.edu
Modelling of various types is increasingly used to measure or predict policy impacts. Cleghorn et $a l^{4}$ constructed a model to understand how 10\% annual tobacco tax increases would affect the New Zealand adult population over a 10 -year period, measuring quality-adjusted life years. They demonstrated that the greatest gains would accrue to the working-age population, with greater benefits for the indigenous Maori population among whom smoking rates are higher. In a study from the UK, ${ }^{5}$ a two-stage modelling process was used to predict future incidence, prevalence and cost of 17 smoking-related diseases if the tobacco duty escalator was increased from $2 \%$ to $5 \%$ above inflation. The authors show that such a policy measure would substantially increase cigarette prices, reduce disease burden and lower health and social care costs related to tobacco use. Another policy measure being increasingly implemented worldwide is point-of-sale display bans. $\mathrm{He}$ et $a l^{6}$ constructed generalised linear models using data from 77 countries to consider impacts on smoking prevalence, demonstrating that such bans reduced overall adult daily smoking, male and female smoking. Such research provides important evidence in support of stronger policy measures to stem the epidemic.

Policies increasing the minimum age for purchasing tobacco have recently become popular in many jurisdictions, but do they play into the tobacco industry's favoured 'forbidden fruit' positioning of their products, making them more attractive to adolescents, or do they effectively reduce the number of adolescents who become smokers? Callaghan et $a l^{7}$ estimated the effects of such a policy on youth smoking, smoking frequency and intensity, and average monthly cigarette consumption. They report that those just above the minimum age limit had 'significant and abrupt' increases in the prevalence of current smokers, compared with those below the age limit. While the authors interpret their findings as providing evidence that such laws will reduce youth smoking, critics might argue that their findings could also be evidence of the 'forbidden fruit' effect and might have the unanticipated consequences of increasing young adult smoking. This points to the importance of messaging in policy research and policy discourse more generally. How we interpret a result and its relevance for policy may well depend on our frame of reference.

In another way of researching potential policy impact, a discrete choice experiment was conducted by Shang et $a l^{8}$ to explore the impact of flavour, device type and health warning messages on youth preference for electronic nicotine delivery systems (ENDS). Fruity and sweet flavours significantly increased the probability of adolescents aged 14-17years saying they would choose ENDS with menthol over tobacco flavour. The authors argue that restriction of flavours in such products could reduce youth uptake.

The cigarette pack as a site for policy intervention is a focus for another two papers. Leas et $\mathrm{al}^{9}$ conducted a between-subject survey experiment to assess whether standardised packaging could reduce the possibility of erroneous 'safety' messages being drawn from the packaging of one popular cigarette brand in the USA, Natural American Spirit. Plain packaging was demonstrated to reduce smokers' ratings of packs on an implied safety scale, even more when Australian-type packaging was used. Another study of packs illustrates the complexity of understanding potential policy impacts. US smokers were randomly assigned to receive either pictorial or text-only health warnings applied to their cigarette packs across a 4-week period, completing a baseline and follow-up survey which measured intentions to quit smoking and several mediating variables. ${ }^{10}$ Pictorial warnings were found to increase quit intentions by increasing negative affect. However, this was partly attenuated by message reactance and thus no changes in perceived risk were found.

Comparative studies often seek to estimate policy impacts by comparing trends across different geographical sites with different tobacco control climates. In a study comparing California, a recognised tobacco control leader, with the rest of the USA, Pierce et $a l^{11}$ demonstrated that every $\$ 1$ increase in cigarette taxes reduced consumption by 4.8 packs/adult/year and every $5 \%$ increase in the proportion of smokers reporting their homes were smokefree was associated with 8.0 packs/adult/ year lower consumption of cigarettes. The authors suggest that California's leadership in dramatically reducing smoking ahead of the rest of the country overall was attributable to early tax and smoke-free policies, but was attenuated later in the study by lack of additional tax increases, a problem recently remedied at the ballot box after a hard-fought initiative campaign. ${ }^{12}$

Benefit-cost analyses are used to appraise proposed policies in advance of 
enactment. For example, in the USA, the Food and Drug Administration is required as part of its rule-making process to conduct an economic benefit-cost analysis. However, a proposed rule requiring graphic warning labels on packs has gone unimplemented partly because a benefitcost analysis suggested the benefits would be seriously reduced by the 'lost pleasure' of smokers who quit as a result. The details of how and what to value in such analyses remain a topic of brisk debate, and Pechacek et $a l^{13}$ examined 2015 US national survey data to further evaluate the assumptions related to 'lost pleasure'. More than $80 \%$ of current smokers reported high or very high discontent due to their inability to quit smoking, perceived addiction and regret about starting to smoke. The authors concluded that those smokers who might be understood as preferring to continue smoking and would thus lose 'pleasure' if the policy was effective in persuading them to quit are far outnumbered by those with high levels of discontent and profound regret.

Policy is never solely determined by research findings, but research plays an important role in establishing the parameters of policy conversations, challenging common assumptions and opening new areas for policy discourse and action, including who benefits and who is burdened by policy change. Understanding policy impacts (or lack thereof) is part of the ongoing process of working towards a world in which health justice drives policy, but this understanding requires thinking about not only what is measured, but how-and what is not measured and why.

Funding The author has not declared a specific grant for this research from any funding agency in the public, commercial or not-for-profit sectors.

Competing interests None declared.

Provenance and peer review Not commissioned; internally peer reviewed.

(c) Author(s) (or their employer(s)) 2018. No commercial re-use. See rights and permissions. Published by BMJ.

\section{Check for updates}

To cite Malone RE. Tob Control 2018;27:e96-e97.

Tob Control 2018;27:e96-e97.

doi:10.1136/tobaccocontrol-2018-054722

\section{REFERENCES}

1 Warner KE, Tam J. The impact of tobacco control research on policy: 20 years of progress. Tob Control 2012;21:103-9.

2 Been JV, Mackay DF, Millett C, et al. Smoke-free legislation and paediatric hospitalisations for acute respiratory tract infections: national quasiexperimental study with unexpected findings and important methodological implications. Tob Control 2018;27:e160-e166.

3 Tauras JA, Chaloupka FJ, Moor G, et al. Effect of the Smoke-Free Illinois Act on casino admissions and revenue. Tob Control 2018;27:e98-e104.

4 Cleghorn CL, Blakely T, Kvizhinadze G, et al. Impact of increasing tobacco taxes on working-age adults: short-term health gain, health equity and cost savings. Tob Control 2018;27:e167-e170.

5 Knuchel-Takano A, Hunt D, Jaccard A, et al. Modelling the implications of reducing smoking prevalence: the benefits of increasing the UK tobacco duty escalator to public health and economic outcomes. Tob Control 2018;27:e124-e129.

6 He Y, Shang C, Huang J, et al. Global evidence on the effect of point-of-sale display bans on smoking prevalence. Tob Control 2018;27:e98-e104.

7 Callaghan RC, Sanches M, Gatley J, et al. Impacts of Canada's minimum age for tobacco sales (MATS) laws on youth smoking behaviour, 2000-2014. Tob Control 2018;27:e105-e109.

8 Shang C, Huang J, Chaloupka FJ, et al. The impact of flavour, device type and warning messages on youth preferences for electronic nicotine delivery systems: evidence from an online discrete choice experiment. Tob Control 2018;27:e152-e159.

9 Leas EC, Pierce JP, Dimofte CV, et al. Standardised cigarette packaging may reduce the implied safety of Natural American Spirit cigarettes. Tob Control 2018:27:e118-e123.

10 Hall MG, Sheeran P, Noar SM, et al. Negative affect, message reactance and perceived risk: how do pictorial cigarette pack warnings change quit intentions? Tob Control 2018;27:e136-e142.

11 Pierce JP, Shi Y, Hendrickson EM, et al. Tobacco control in California compared with the rest of the USA: trends in adult per capita cigarette consumption. Tob Control 2017;27:e112-e117.

12 Dillon L. Proposition 56, a \$2-per-pack boost to tobacco taxes, is approved by voters: Los Angeles Times, 2016. http://www.latimes.com/nation/politics/ trailguide/la-na-election-day-2016-proposition-56-2per-pack-cigarette-1478276231-htmlstory.html\#nt= card.

13 Pechacek TF, Nayak P, Slovic P, et al. Reassessing the importance of 'lost pleasure' associated with smoking cessation: implications for social welfare and policy. Tob Control 2018;27:e143-e151. 